Artigo

\title{
MOBILIZAÇÃO E REPRESENTAÇÃO: DINÂMICAS DA PARTICIPAÇÃO SOCIAL NO JOGO DEMOCRÁTICO EM JUAZEIRO - BA
}

\author{
MOBILIZATION AND REPRESENTATION: DYNAMICS OF SOCIAL \\ PARTICIPATION IN THE DEMOCRATIC GAME IN JUAZEIRO - BA
MOVILIZACIÓN Y REPRESENTACIÓN: DINÁMICA DE LA PARTICIPACIÓN SOCIAL EN EL JUEGO DEMOCRÁTICO EN JUAZEIRO - BA

\author{
Cláudio Roberto dos Santos de Almeida
}

\begin{abstract}
Resumo
O presente artigo visa analisar o modo como a Esfera Pública tem sido constituída em Juazeiro e Petrolina (as duas cidades mais importantes do Sub-Médio São Francisco) a partir da atuação das associações organizadas em torno da experiência étnico-racial nestas cidades. O pano de fundo da presente análise consiste na compreensão de como estas cidades florescem enquanto ambientes nos quais se desdobram os processos interativos e identitários, direcionados à apresentação de demandas sociais ao Poder Público na região. Será feita uma análise das atuais possibilidades de incorporação das demandas das associações pelas administrações municipais locais e do modo como os dois munícipios têm lidado com legendas relacionadas às relações raciais. Para isto será alvo de atenção a dinâmica de atuação das organizações da sociedade civil e as ações do Estado no que tange à forma como a questão racial é interpretada e tratada por estes dois agentes.
\end{abstract}

\begin{abstract}
This article aims to analyze how the Public Sphere has been constituted in Juazeiro and Petrolina (the two most important cities in the Sub-Middle São Francisco) from the actions of associations organized around the racial/ethnic experience in these cities. The background of this analysis is the understanding of that cities flourished as places where it unfold the interactive and identity processes, directed to the presentation of social demands to the Public Power in the region. An analysis will be made of the current possibilities for incorporating the demands of the associations by the local municipal administrations and the way that these cities have dealt with legends related to race relations. To this end, the dynamics of action of civil society organizations and the actions of the State regarding the way in which the racial issue is interpreted and treated by these two agents will receive attention.
\end{abstract}

\section{Resumen}

Este artículo tiene como objetivo analizar la forma en que se ha constituido la Esfera Pública en Juazeiro y Petrolina (las dos ciudades más importantes del Sub-Medio de São Francisco) a partir de las acciones de las asociaciones organizadas en torno a la experiencia étnico-racial en estas ciudades. El trasfondo del presente análisis consiste en la comprensión de cómo estas ciudades florecen como entornos en los que se desarrollan los procesos interactivos y de identidad, dirigidos a la presentación de demandas sociales al Poder Público en la región. Se analizará las posibilidades actuales para incorporar las demandas de las asociaciones por parte de las administraciones municipales locales y la forma en que los dos municipios han tratado las leyendas relacionadas con las relaciones raciales. Con este fin, recibirán atención las dinámicas 
de acción de las organizaciones de la sociedad civil y las acciones del Estado con respecto a la forma en que estos dos agentes interpretan y tratan el problema racial.

Palavras-Chave: Vale do São Francisco; Urbanidade; Esfera Pública; Associativismo Étnico; Participação.

Keywords: São Francisco Valley; Urbanity; Public Sphere; Ethnic Associations; Participation.

Palabras clave: Valle de São Francisco; Urbanidad; Esfera pública; Asociaciones étnicas; Participación

\section{INTRODUÇÃO}

Este trabalho é fruto de uma pesquisa em andamento realizada sob minha orientação que tem por finalidade compreender os modos de intervenção de grupos étnico/culturais organizados no Espaço Urbano e na Esfera Pública de Juazeiro (BA) e Petrolina (PE). ${ }^{1}$ A pesquisa está voltada para o mapeamento e caracterização das formas de atuação de grupos sociais organizados em torno de relações raciais no espaço urbano das duas cidades. Em sua fase inicial, foi realizado um mapeamento e uma reconstituição analítica do processo de formação das principais organizações civis que atuam na promoção da igualdade racial ou combate ao racismo nas duas cidades. Como desdobramento das observações a respeito da dinâmica de atuação das organizações civis com base em experiências étnico-raciais do Vale do São Francisco, torna-se importante uma reflexão sobre as possibilidades de alcance de resultados concretos em termos de ação do poder público no tocante às bandeiras defendidas por tais grupos.

A opção por analisar a atuação das organizações sociais com base em experiências de raça em Juazeiro e Petrolina como modo de compreender como se dá a formação da Esfera Pública na região do Vale do São Francisco se deu por dois fatores principais. Primeiramente, o foco analítico nas cidades de Juazeiro e Petrolina explica-se pela predominância econômica e importância política destas duas cidades na Região integrada de Desenvolvimento Econômico do Vale do São Francisco (RIDE) ${ }^{2}$. Com um efetivo populacional que supera 400 mil habitantes, as duas tem sido local destino de constante fluxo migratório e respondem por boa parcela das mobilizações políticas locais. $\mathrm{O}$ segundo elemento condicionante desta escolha é o fato de que, com uma concentração de $67 \%$ de negros em Petrolina e $73 \%$ em Juazeiro ${ }^{3}$, os problemas relacionados às desigualdades sociais locais (assim como em boa parcela do país) se desenvolvem sob o escopo de diferenciações sociais orientados por critérios de raça, assim como de gênero.

\section{URBANIDADE E ESFERA PÚBLICA}

O conceito de Esfera Pública tem sido amplamente discutido tanto entre pesquisadores ligados ao pensamento político quanto entre aqueles que se

\footnotetext{
${ }^{1}$ A pesquisa conta com apoio do CNPQ, FACEPE e FAPESB sob forma de concessão de bolsas de iniciação Científica.

${ }^{2}$ A RIDE abrange as cidades de Casa Nova, Santa Maria da Boa Vista em Pernambuco e Curaçá, Sobradinho na Bahia.

${ }^{3}$ Segundo senso IBGE 2010.
} 
identificam mais com a assim chamada Teoria Social. Em boa medida, a razão pela qual este conceito tem sido discutido é a própria dinâmica política contemporânea, marcada pela atuação de diferentes organizações civis no mundo inteiro e o clamor para que suas reivindicações encontrem ressonância das medidas tomadas pelo Estado em diferentes acepções. Um dos mais proeminentes teóricos que tem oferecido contribuições para um esclarecimento a respeito do conceito de esfera pública é Jurgen Habermas (2003), filósofo alemão profundamente preocupado com as possibilidades concretas de exercício da democracia nas sociedades ocidentais.

O conceito de Esfera Pública emerge na teoria habermasiana em um conjunto de preocupações relativas ao advento das sociedades modernas. Segundo o autor a Esfera Pública inicia-se no momento em que, com o alto grau de densidade demográfica e complexidade moral das sociedades capitalistas, 0 Estado passa a assumir a função de regulação das relações comerciais e intersubjetivas. Esta adquire legitimidade na medida em que grupos de concidadãos se reúnem para discutir questões relativas às decisões públicas sobre a vida em sociedade e tentar impor limites ao Estado Absolutista.

De maneira geral, as possibilidades concretas de um desenvolvimento adequado da Esfera Pública se deram com o advento do capitalismo justamente por este ter promovido mudanças sociais significativas nos países europeus. Com o progressivo afastamento do Estado em relação aos interesses e à capacidade de intervenção dos cidadãos em suas decisões (desdobramentos do liberalismo político), a Esfera Pública surge como um espaço privilegiado de religação entre o sistema e o mundo da vida. Este é por excelência um espaço de formação da opinião política e encontra nas sociedades liberais os parlamentos e esferas legislativas como instituições que podem promover 0 diálogo sociedade/Estado.

No Brasil, é possível encontrar registros de uso da vida pública desde muito cedo. Já em alguns centros urbanos mais estruturados no século XVIII havia levantes populares que utilizavam a via pública como espaço de transmissão de informações e ideias. Porém, a Esfera Pública no Brasil viveu momento de intensa transformação no limiar do século XIX. Seu marco histórico e sociológico foram as transformações ocorridas pelo menos nas cidades mais proeminentes a partir da chegada da família real em 1808. Este período em que o Brasil torna-se sede do império português é marcado por dois grandes processos simultâneos. Por um lado, tem-se o enfraquecimento do poderio da economia centrada na produção de açúcar e a já notável emergência da economia cafeeira - o proporcionou um deslocamento do poder político da região nordeste para o sudeste - onde foi implantado o centro administrativo do país. É em meados do século XIX que as cidades brasileiras deixam de ser locais em que se davam encontros para se tornarem locais feitos para isto promoveram assim o convício social entre diferentes grupos e com interesses diversificados.

Os fatores anteriormente descritos se mostraram como condição fundamental para o desenvolvimento de preocupações quanto à coletividade e de constituição efetiva de uma Esfera Pública, principalmente por aqueles que haviam adotado aquilo que Florestan Fernandes (2010) considerou como a "utopia burguesa" (abolicionistas, republicanistas etc.). Porém, as possibilidades reais de uma complexificação da vida política e da participação popular nas decisões de Estado no Brasil foram limitadas por muito tempo devido à restrição 
dos direitos civis (liberdade, integridade, igualdade etc.), dos direitos sociais (moradia, educação, emprego etc.) e dos direitos políticos (voto, organização partidária etc.) à grande maioria da população, composta principalmente por escravizados, mulheres e pessoas sem alfabetização.

Como consequência deste modelo de formação social e da prevalência do patrimonialismo, o Brasil enfrentou e ainda enfrenta dificuldades no tocante a um processo de ampliação dos espaços de decisão compartilhada e apresentação de demandas coletivas. A vida política no país é ainda muito fortemente marcada por uma desconfiança em relação ao legislativo (câmaras municipais, estaduais e federais), uma hierarquização da vida pública a partir de critérios de raça, classe e gênero e uma aposta na capacidade da esfera executiva do Estado no tocante à resolução dos problemas sociais que afetam a população.

Segundo José Murillo de Carvalho (2001), o timming e o modo com que aconteceram estas conquistas definiu em grande medida o caráter relação sociedade/Estado e os princípios da cidadania nos países. Em alguns casos como o inglês, por exemplo, a cidadania foi conquistada a partir de uma atuação efetiva da população e do exercício livre do poder judiciário. Nestes casos, os direitos civis garantiram, uma ampliação dos direitos políticos e abriu-se brechas para a ampliação dos direitos sociais. Em outros exemplos, como o caso Brasil pós 1930, houve uma supressão dos direitos políticos e expansão precoce dos direitos sociais via Estado, constituindo o que o autor classificou como uma "estadania" (2001, p.115).

Esta conquista de direitos sociais básicos via ação exclusiva do Estado acabou por reforçar toda uma lógica paternalista e centralizadora que minou pela base a possibilidades emancipatórias das organizações civis durante longo período da história nacional. Atualmente, pós-constituição 1988, as organizações sociais reorganizam-se sobre outras bases de reivindicação, buscando formas participativas de intervenção na vida pública. Analisar como tem se dado esta dinâmica nas diferentes realidades significa averiguar as possibilidades reais e limites de exercício da democracia atualmente no país.

\section{MODERNIZAÇÃO CONSERVADORA, ESPAÇO URBANO E A EMERGÊNCIA DE NOVAS DINÂMICAS COLETIVAS DE CONTESTAÇÃO NO VALE DO SÃO FRANCISCO}

A região do Sub-Médio São Francisco tem chamado a atenção de especialistas e leigos devido ao notável processo de modernização e desenvolvimento econômico local. O crescimento econômico da região do Vale do São Francisco tem sido impulsionado por programas e políticas desenvolvimentistas implantados na região há cerca de 50 anos. $O$ foco por excelência destas estratégias de modernização tem sido o aprimoramento das técnicas e instrumentos de produção agropecuária, voltado para o aumento da produção e a sustentação de mercados regionais, nacionais e internacionais (Franca, 2008).

As políticas de modernização econômica implantadas nos últimos trinta anos têm exercido influência sobre diferentes aspectos da região, seguindo uma lógica já observada em diferentes localidades do país. O processo de desenvolvimento regional do Vale do São Francisco tem sido orientado por um modelo de crescimento econômico e acumulação capitalista pautado na 
distribuição desigual da renda e na hierarquização social do acesso aos bens escassos da sociedade - modelo este que foi implementado em diferentes escalas na história econômico/social do Brasil. Desta maneira, é possível afirmar que o Vale do São Francisco é marcado por aquilo que Domingues (2004) descreveu se referindo ao desenvolvimento econômico nacional como um processo e Modernização Conservadora. Este processo se traduz num cenário marcado pela convivência entre novas formas urbanas e rurais de sociabilidade e modelos autoritários de relações trabalhistas, raciais, de gênero etc.

Dentre estas principais influências, é possível destacar as novas dinâmicas demográficas proporcionadas pelos fluxos migratórios de trabalhadores de diferentes níveis de especialização para a região. Por um lado, migração de trabalhadores não especializados abastece a região de um contingente de mão-de-obra de baixa qualificação que é geralmente utilizada para a oferta de serviços braçais e outros a baixo custo. Estes trabalhadores se aglutinam em regiões periféricas das cidades, próximas às zonas de produção agrária, formando ocupações irregulares que, em alguns casos, dão origem a novos bairros populares.

Considerando a atuação dos dois principais agentes de crescimento físico e demográfico de Petrolina e Juazeiro (o Estado e o Mercado) o processo de crescimento destas cidades, é possível assistir a uma lógica de crescimento urbano marcada pela privatização dos espaços de sociabilidade (com 0 surgimento de condomínios, clubes, restaurantes, bares e o não investimento em equipamentos públicos de lazer como praça etc.) e uma redução do potencial interativo que a própria cidade pode proporcionar, colocando em cheque as próprias possibilidades de um desenvolvimento mais aprimorado da Esfera Pública na região.

Este processo de Modernização Conservadora e Urbanização da região é ainda contextualizado por um fenômeno mais geral de globalização que tem afetado boa parte das localidades no mundo contemporâneo. Este processo é marcado pela fragmentação e individualização de identidades tradicionais, bem como pela tentativa de homogeneização cultural das diferentes localidades do mundo numa comunidade global integrada. Contraditoriamente, é sabido que este mesmo processo de homogeneização cultural tem como um dos principais desdobramentos o retorno de indivíduos e grupos às identidades étnico/culturais tradicionais e a inserção da luta pela sua legitimação política e preservação (Santos, 2010; 2008; Sansone, 2008; Gohn, 2008; 2007; Habermas 1994). O jogo democrático na região passa cada vez mais a ser regido também pela busca do Reconhecimento cultural, como bem analisou Fazer (2001) sobre o contexto das mobilizações pós-classistas contemporâneas.

Por outro lado, modernização da região também vem acompanhada da chegada ou aprimoramento de instituições públicas que garantem direitos e benefícios sociais à população local. A ação destas instituições, bem como a crescente demanda por modelos mais igualitários de relações sociais vem incentivando e possibilitando a ação de grupos sociais organizados na busca por cidadania e integração social. Isto implica na abertura para os grupos sociais de novas maneiras de intervenção na Esfera Pública local, estabelecendo estratégias contestatórias e identitárias no espaço público destas cidades. $O$ processo que se tem assistido a partir da intervenção das associações na região é a tentativa de garantir justamente que este processo de modernização possa 
proporcionar uma integração social de grupos socialmente excluídos, como é o caso dos grupos étnico/raciais no Vale do São Francisco.

\section{FORMAÇÃO E DINÂMICA ASSOCIATIVA ÉTNICO/RACIAL DOS PRINCIPAIS GRUPOS DE ATUAÇÃO NA REGIÃO}

Quando analisamos a trajetória das principais associações de Petrolina e Juazeiro, podemos destacar fatores mais ou menos comuns e elementos específicos que caracterizam o momento político, as inclinações culturais e até mesmo as interpretações sobre o método e o significado da lua política para cada um dos membros nestas associações. De modo geral, ainda que por vias diferentes, as associações de Petrolina se organizam em torno da experiência religiosa, enquanto as organizações de Juazeiro estão mais ligadas a experiências de atuação no setor cultural ou da militância política. Para dar mais embasamento à afirmação presente, será necessária uma breve apresentação das principais associações atuantes em cada uma das cidades.

Uma das mais antigas e participativas associações da região é $A$ Associação das Mulheres Rendeiras do Bairro de José e Maria em Petrolina. A Associação tem sua origem num grupo de mobilizações formado em torno da defesa do direito dos moradores da habitação informal conhecida à época como Vila Papelão. Há cerca de três anos, a Associação das Mulheres Rendeiras formou o Ponto de Cultura os Heróis do Povo Negro com objetivo de garantir visibilidade à história da população afrodescendente no Brasil e no mundo.

Outra importante associação de Petrolina é a Associação Espírita e de Cultos Afro-Brasileiros. Esta se formou num período em que, dado o processo de expansão urbana das cidades, muitas casas de culto, que antes ficavam relativamente isoladas do centro da cidade, passaram a integrar bairros novos que cresciam em torno da propriedade em que os terreiros estavam instalados. Com o aumento da quantidade de moradores nestes novos bairros e a dificuldade de manter relações vicinais amistosas, as casas de culto passaram a conviver com constantes conflitos que muitas vezes envolviam a ação do judiciário na tentativa de resolução de conflitos. Em sua fase inicial, a associação estava bastante preocupada com a necessidade de valorização e respeito a suas práticas religiosas, tendo redirecionado seu discurso para uma abordagem racialmente orientada ao decorrer de sua trajetória.

O NAENDA, por sua vez, foi formado a partir de um grupo de teatro de rua no final da década de 1980. Só depois, já nos anos 2000, com o apoio da secretaria de cultura do município de Juazeiro em uma gestão do Partido dos Trabalhadores (PT), o NAENDA se formou com o objetivo inicial de promover a conscientização da população através da arte-educação. O mais recente grupo é o North Bahia Crew, um coletivo de jovens aderentes à cultura Hip Hop oriundos de diferentes bairros pobres da região que se organiza em torno da defesa do direito da juventude (e em especial a juventude negra) aos benefícios da cidade, de direitos sociais até então não garantidos pelo poder público e da necessidade de fortalecimento da autoestima de seus participantes.

Analisando o processo de formação das principais associações de defesa de bandeiras étnico-raciais em Petrolina e Juazeiro, foi possível observar elementos comuns em seu processo formativo, suas atividades e métodos de trabalho. De modo geral, as associações se formaram em um período marcado por uma retomada das lutas políticas pelos movimentos sociais e por uma 
reocupação do espaço público como local por excelência de formação da opinião política e das ações contestatórias em todo o país. No caso da região em análise, o passado político recente da região) estabeleceu um conjunto de fatores podem ser vistos como importantes elementos na condução dos processos de retomadas das organizações associativas e participativas locais. Muito da formação destes grupos pode ser compreendido sob a ótica do processo de desenvolvimento urbano da região.

Nos últimos três anos a luta antirracista vem sendo realimentada por meio do ativismo blogger e das mobilizações a partir da experiência universitária. A expansão do ensino superior, alinhada à adoção de ações afirmativas redirecionou parte das atenções políticas da juventude negra para elementos relacionados à experiência acadêmica. Assim, é possível identificar as universidades e institutos federais locais como importantes centros de radiação de ações contestatórias e auto afirmativas, marcando aquilo que Honneth (2003) classificou como sendo uma modificação na gramática moral dos processos contestatórios. Esta seria a inserção da percepção das diferenças de experiências culturais em um conjunto de ações de Estado voltadas para a sua preservação, ou como bem avaliou D'Adesky (2009), a transição de um pluralismo étnico para uma perspectiva multiculturalista.

Debates como diversidade sexual, políticas afirmativas, bem como outras legendas de aprofundamento da dinâmica democrática vêm sendo travados por meio de grupos de mobilização e estudo. Desta maneira, é possível falar de uma nova tendência de mobilização dos grupos políticos. Qual seja, a disputa interna contra a hegemonia branco-normativa nos centros de produção de conhecimento e a concomitante tentativa de recrutamento de novos atores fora destes espaços - isto por meio de eventos em locais públicos e pela confecção de alianças com outros grupos de mobilização externos à universidade.

Um exemplo interessante deste novo momento são grupos como $O$ Coletivo de Mulheres Negras do Vale e o Coletivo de Movimentos Anti-Racistas do Vale (MAV). Estes dois grupos possuem seu epicentro político em experiências da universidade, porém estendem suas atuações para diferentes zonas de interlocução, como escolas, associações profissionais etc. uma das maiores marcas destes grupos diz respeito à defesa na localidade de pautas que se articulam com mobilizações nacionais - tais como a crítica ao afro-genocídio, a defesa das novas demandas políticas relacionadas à experiência das mulheres negras e a luta pela diversidade sexual e religiosa.

Neste sentido, é possível encontrar dois grandes vetores de mobilização política na região. Por um lado nota-se a cada vez mais crescente atuação política por grupos como os já descritos, sendo estes relativamente pouco numerosos e se organizando em torno de pautas que possuem incidência no cotidiano das pessoas - às vezes em ações expressivas mais setorizadas (bairros, associações etc). Por outro lado, também nota-se a tentativa de ocupação de espaços estratégicos de decisão política, como Conselhos, Gabinetes etc., como será visto na próxima seção.

\section{MOBILIZAÇÃO E PARTICIPAÇÃO NO PODER PÚBLICO LOCAL}

Petrolina e Juazeiro são duas cidades que, embora possuam histórias políticas mais ou menos diferenciadas, apresentam características muito semelhantes quando observadas suas possibilidades de um diálogo mais amplo 
com as organizações da sociedade civil. Para uma compreensão mais adequada do atual quadro de relação sociedade/poder publico nestas cidades, é necessária uma compreensão de como esta dinâmica tem se configurado ao nível dos estados como um todo.

De modo geral, a literatura sobre participação política e relação Sociedade/Estado no Nordeste está bastante influenciada por um discurso oficial criado e retroalimentado no seio das próprias ciências sociais brasileiras no que diz respeito à região Nordeste (Avritzer, 2007). No bojo destas discussões estão representações mais gerais que identificam a atrofia econômica à permanência do patriarcalismo de origem, criando uma imagem do Nordeste como região economicamente inviável e politicamente arcaica. Quando considerados os fatos de que, o Nordeste contemporâneo é a região que mais apresenta crescimento econômico no país e que tem tido uma importante participação nas decisões eleitorais nos últimos anos, principalmente desbancando certos setores conservadores então presentes, esta imagem começa a se tornar cada vez mais frágil.

Esta constatação não quer dizer que as características então descritas na região Nordeste não se encontram presentes, principalmente em cidades mais distantes das capitais, como Juazeiro e Petrolina. Porém, para uma compreensão adequada da relação sociedade civil/poder público nesta região, é necessário atentar para o modo como estes modelos antigos de organização estrutural da vida pública tem sido combatido ou reafirmado pela lógica de correlação entre os grupos políticos e pela ação das organizações civis. Tal análise se torna importante quando observado que, conforme salienta Avritzer (2007), a forma e a habilidade participativa das organizações civis estão ligadas com o modo como o poder público se relaciona com a sociedade civil em seus processos decisórios.

Consideradas suas relações com a política mais ampla que se desenvolve nos estados, Petrolina e Juazeiro possuem características bastante peculiares. Petrolina apresenta-se como uma cidade com características de participação que contradiz uma tendência geral que se tem constituído no estado de Pernambuco já há algumas décadas. Juazeiro, por sua vez, segue uma lógica de relação sociedade/estado muito similar à que a Bahia tem constituído no mesmo período. De um lado da ponte, no caso de Petrolina, há uma tendência de retração das instituições e organizações participativas contradizendo a lógica geral do estado. Do outro, há a reprodução de um modelo mais ou menos estabelecido em toda a unidade subnacional, com esforços locais de reversão do quadro.

A história política de Pernambuco tem sido profundamente marcada pela emergência de organizações e instituições participativas desde a década de 1950. Com a abertura democrática e a intensificação das lutas relacionadas a problemas urbanos na década de 1980, o Estado assistiu a um processo de espraiamento de associações, o que influenciou a ampliação de mecanismos de estreitamento da relação sociedade/estado, principalmente sob a legenda do orçamento participativo. O estado de Pernambuco é um dos que se destacam na região nordeste por ter seguido uma tendência geral do chamado boom participativo que caracterizou o Sul/Sudeste no mesmo período. Sendo assim, cidades de menor porte passaram a seguir o modelo de relação com o poder público estabelecido por esta tendência geral. 
A vida política de Petrolina neste período não conseguiu acompanhar as legendas do boom associativo, o jogo político era bastante orientado pela lógica das relações interfamiliais e oligopolizado por uma parcela bastante restrita da população local. Neste contexto as possibilidades de participação da sociedade civil na dinâmica política local estavam limitadas à lógica das filiações por interesse pessoal ou ao corporativismo de alguns grupos mais ou menos autônomos. O poder público de Petrolina é hoje disputado por três grandes tendências: setores ligados às antigas oligarquias agrárias que estão comprometidas com a implantação do desenvolvimento econômico (principalmente na produção rural) e que buscam manter o controle dos processos decisórios a nível local e estadual; setores do empresariado e de profissionais liberais do meio urbano que buscam romper com o monopólio político dos setores tradicionais, ainda que mantenham uma legenda relativamente conservadora e, em, terceiro lugar, há forças políticas ligadas a partidos de esquerda (principalmente o PT) e que buscam chamar atenção para as demandas reprimidas da população e para as dificuldades abertas pelo novo momento econômico por que passa a cidade. Em geral estas três forças possuem representantes no setor legislativo da cidade, ainda que em proporções pouco equilibradas.

As forças políticas conservadoras ligadas às atividades econômicas urbanas e da esquerda têm tentado manter diálogos com a população local, porém tem sido recorrentemente acusadas por setores mais esclarecidos da militância de não conseguirem estabelecer relações mais orgânicas com suas demandas. De modo geral, a apresentação de temas de debate à Câmara tem sido mais encaminhada pela intermediação que a mídia local tem feito, que chama a atenção para problemas estruturais da cidade, que de fato a partir de uma construção dialógica com as associações.

Juazeiro não apresenta um quadro muito diferente. A história política de Juazeiro nos últimos anos está bastante relacionada com a emergência e declínio da abrangência do "carlismo" no estado da Bahia. O carlismo foi um modelo de arranjo político criado em torno da figura de Antônio Carlos Magalhães (ACM), um importante líder político baiano que constituiu sua trajetória no poder a partir da formação de uma ampla rede de favorecimentos de simpatizantes e perseguição de opositores ao longo dos últimos 40 anos.

Uma característica importante do carlismo é que este se constituiu a partir de uma dinâmica bastante volátil de alianças com as oligarquias em voga em cada região, fortalecendo o seu predomínio e reprimindo as vozes dissidentes em cada uma das localidades como forma de adquirir fidelidade política destes grupos. Como consequência deste arranjo político, o carlismo criou uma estrutura de governo absolutamente refratária à participação popular, seja por meio de instituições de diálogo sociedade/estado (como os conselhos etc.), seja pela garantia de expressão livre e pública da opinião por grupos contestatórios. Cooptação, corrupção e violência policial se tornaram a marca por excelência do predomínio do carlismo na Bahia. A dinâmica política de Juazeiro hoje está bastante orientada em torno da relação carlismo/anti-carlismo, conforme podese notar em diferentes municípios do estado como uma tendência geral do jogo político local (Milani, 2007; Mota, 2007). Embora, com a morte de ACM o carlismo tenha se atrofiado, este modelo deixou como legado um conjunto de articulações entre os setores conservadores locais voltados para a manutenção 
do predomínio político das oligarquias formadas ou fortalecidas em seu período áureo.

Diante destas heranças históricas, Petrolina e Juazeiro hoje têm apresentado uma dinâmica de relação Estado/Sociedade Civil ainda bastante incipiente. Além da dificuldade de incorporação das demandas étnico/culturais nas plataformas políticas dos vereadores e prefeitos é possível destacar um outro elemento de complicação do quadro. Como provável reflexo da emergência de governos de inclinação popular a nível estadual e nacional nos últimos anos, as cidades de Petrolina e Juazeiro têm vivido um processo de emergência de representações políticas mais ligadas às associações nas últimas eleições. Este fenômeno tem implicado numa dinâmica de alocamento das principais lideranças dos grupos político/culturais na estrutura de governo dos municípios, como forma de garantia de uma relação mais estreita com as bases.

Ou seja, na medida em que vereadores e prefeitos discursivamente comprometidos com as demandas populares (não necessariamente de esquerda) conseguem galgar cadeiras no legislativo e executivo local, os líderes mais conhecidos dos grupos têm sido incumbidos da tarefa de promover a mediação entre as figuras públicas e a população em geral. Contraditoriamente, o aumento da participação política dos grupos étnicos tem implicado numa hipertrofia do eixo da representação e um decréscimo da capacidade organizativa do eixo da mobilização, devido a sua defasagem. Esta pode ser uma das maiores dificuldades de estabelecimento de uma legenda participativa nas duas cidades: além de um quadro geral de insensibilidade às demandas sociais por parte dos setores majoritários, tem havido um processo de esvaziamento dos grupos de mobilização e uma dificuldade de equacionar a relação sociedade civil/poder público nestas cidades.

\section{CONSIDERAÇÕES FINAIS}

Muitos são os desafios postos a uma complexificação da Esfera Pública em Petrolina e Juazeiro. De modo geral, as dificuldades salientadas neste texto possuem origens históricas muito específicas e, como tais, podem ser revertidas. O momento atual tem sido marcado pela emergência de grupos políticos orientados por diferentes legendas de mobilização. Do mesmo modo as administrações têm desprendido esforços para resolver os problemas de diálogo com a sociedade civil, reservadas as devidas ressalvas, evidentemente. A questão fundamental é que as mobilizações políticas nas duas cidades estão cada vez mais antenadas com processos gerais ocorridos em outras cidades do Brasil, principalmente as capitais. $\mathrm{E}$, na medida em que isto ocorre, a denúncia ao caráter arcaico do modelo atual de relação sociedade/estado executado nos municípios se torna um fator quase inevitável.

Este grau de insatisfação vem sendo manifestado por meio de ações principalmente culturais que vêm atentando para o caráter estratégico da participação política da juventude desde as manifestações de 2013. Porém, embora seja possível identificar um grau de envolvimento dos setores da juventude em questões políticas, estas ainda se encontram relativamente orientadas por pautas mais gerais, absorvidas em suas experiências no cenário cultural e acadêmico da região.

Mesmo com estas características é possível notar na região do Sub-Médio São Francisco uma tendência que se tem constituído nas duas cidades e que 
pode descrever em maior ou menor grau processos que em desdobramento no período atual nas cidades de pequeno porte, pelo menos no Nordeste brasileiro. O processo de aceleração do crescimento econômico nestas localidades tem contextualizado um fenômeno paralelo de complexificação das relações sociais, com a ampliação de instituições democráticas (Conselhos, Delegacias Especiais, Ministério Público etc.) e a emergência de novos atores e mecanismos de atuação na Esfera Pública. Com isto, surgem também demandas para um reequilíbrio das forças políticas locais, onde a sociedade civil organizada passa a demandar cada vez mais sua participação nos processos decisórios das cidades.

O processo de impeachment da então presidente Dilma Rousseff e a sucessão de eventos políticos orientados pela relação Judiciário/Legislativo criou um cenário de esgotamento da Esfera Pública como instrumento de interlocução Sociedade Civil/Executivo. De maneira geral, podemos falar de uma retração da Esfera Pública como categoria política e a redução do político à esfera dos espaços insulados pelo modelo republicano de administração de poderes. Com isso as mobilizações políticas locais têm se movido muito mais para bandeiras que possuem maior possibilidade de resultados concretos (como aquelas relacionadas ao cotidiano) e de certa maneira secundarizando os espaços institucionais de radiação/recepção de discursos contestatórios. Não se sabe ainda quais diretrizes de ação política podem se consolidar em futuro próximo. É possível que a perda de uma relação mais forte com o executivo federal venha a acarretar em um retorno à municipalidade como estratégia de ganhos políticos, ou mesmo que os movimentos assumam pautas mais genéricas e passíveis de constituição de alianças. O cenário futuro das ações contestatórias e mobilizações antirracistas no Vale do São Francisco permanece tão difícil de se inferir quanto os possíveis direcionamentos que terão os processos políticos mais hegemônicos no país. O momento atual parece ser de reformulação de estratégias e práticas num contexto de cada vez mais insólitas possibilidades efetivas de resultados concretos.

\section{REFERÊNCIAS}

AVTRIZER, Leonardo. A participação social no Nordeste. In: (Org.)

A participação social no Nordeste. Belo Horizonte: UFMG, 2007. 1996.

CARVALHO, José Murilo de. Cidadania no Brasil: o longo caminho. Rio de janeiro: Civilização Brasileira, 2006.

D'ADESKY, Jackes. Racismos e Anti-Racismos no Brasil: Pluralismo Étnico e Multiculturalismo. Rio de Janeiro: Pallas, 2009.

DOMINGUES, José Maurício. A Dialética da Modernização Conservadora e a Nova História do Brasil. In: Domingues, Maurício. Ensaios de Sociologia: Teoria e Pesquisa. Belo Horizonte: UFMG, 2004.

FERNANDES, Florestan. A Revolução Burguesa no Brasil: Ensaio de Interpretação Sociológica. São Paulo: Editora Globo, 2010. 
FRANCA, Celso. A Imagem do Vale: Reestruturação Agrícola e Mudança Social. Juazeiro: Editora Franciscana, 2008.

FRASER, Nancy. Da redistribuição ao Reconhecimento?: dilemas da justiça na era pós-socialista. Brasília: Editora UNB, 2001.

GOHN, Maria da Glória. Teoria de Movimentos Sociais: paradigmas clássicos e contemporâneos São Paulo: Edições Loyola, 2008.

Movimentos Sociais no Início do Século XXI: antigos e novos atores. Petrópolis: Vozes, 2007.

HABERMAS, Jürgen. Mudança Estrutural da Esfera Pública. Rio da Janeiro: Tempo Brasileiro, 2003.

Lutas por Reconhecimento no Estado Constitucional Democrático. In: _ TAYLOR, Charles (org). Multiculturalismo. Lisboa: Instuto Piaget, 1994.

HONNETH, AXEL. Luta por Reconhecimento: A gramática moral dos conflitos políticos. São Paulo: Editora 34, 2003.

MILANI, Carlos. Participação social e Ação Publica na Bahia. In: AVTRIZER, Leonardo. (org). A participação SOCIAL no Nordeste. Belo Horizonte: UFMG, 2007.

MOTA, Aurea. Fissuras na Estrutura do Mandonismo: transformações recentes e ampliação do escopo democrático na Bahia. In: AVTRIZER, Leonardo. (org). A Participação Social no Nordeste. Belo Horizonte: UFMG, 2007.

SANTOS, Boaventura de Souza (org). Reconhecer para Libertar: os caminhos do cosmopolitismo multicultural. Rio de Janeiro: Civilização Brasileira, 2010.

Pela mão de Alice: o Social e o Político na Pós-Modernidade. São Paulo: Ed. Cortez, 2008. 